13

\title{
Неравномерная упругая деформация и мемристорный эффект в ориентированных углеродных нанотрубках
}

\author{
() М.В. Ильина, О.И. Ильин, Ю.Ф. Блинов, В.А. Смирнов, О.А. Агеев
}

Южный федеральный университет, НОЦ „Нанотехнологии“, 347922 Таганрог, Россия

e-mail: mailina@sfedu.ru, ageev@sfedu.ru

(Поступило в Редакцию 18 апреля 2017 г. В окончательной редакции 24 марта 2018 г.)

\begin{abstract}
Представлены результаты моделирования упругой деформации ориентированной углеродной нанотрубки под действием локального внешнего электрического поля. Разработана методика формирования контролируемой неравномерной упругой деформации в вертикально ориентированной углеродной нанотрубке, которая является необходимым условием для проявления воспроизводимого мемристорного эффекта в нанотрубке. Проведены экспериментальные исследования токопрохождения в упруго деформированных углеродных нанотрубках с аспектным отношением от 20 до 30. Показано, что увеличение значения относительной деформации нанотрубки от 0.02 до $0.07 \%$ вызывает увеличение ее сопротивления в высокоомном состоянии в 5.2 раза за счет роста внутреннего электрического поля, что приводит к усилению мемристорного эффекта в ней.
\end{abstract}

DOI: 10.21883/JTF.2018.11.46637.2301

\section{Введение}

Развитие современной электроники связано с постоянным повышением быстродействия, энергоэффективности и степени интеграции запоминающих устройств [1-4]. Одним из перспективных направлений в этой области является разработка и исследование мемристорных структур на основе наноматериалов и наноструктур [4-8]. Благодаря своим уникальным электрическим и механическим свойствам, а также совместимостью метода получения с групповой технологией микроэлектроники, особый интерес среди наноструктур представляют углеродные нанотрубки (УНТ), ориентированные между электродами в вертикальном или горизонтальном направлениях $[9,10]$.

Проведенные экспериментальные исследования показали, что индивидуальные ориентированные углеродные нанотрубки проявляют воспроизводимый мемристорный эффект, связанный с их деформацией и возникновением внутреннего электрического поля $[11,12]$. Также имеются сообщения о наблюдении эффекта переключения сопротивления при исследовании эмиссионных характеристик массивов вертикально ориентированных УНТ [13-16] и при исследовании пучков УНТ методом сканирующей туннельной микроскопии (СТМ) [17]. При этом переключение сопротивления УНТ происходило из высокоомного в низкоомное состояние, что не согласуется с теорией электромеханического эффекта, проявляющегося в увеличении сопротивления УНТ в процессе ее деформации [18].

Анализ публикаций [11-19] показал, что необходимым условием проявления мемристорного эффекта является предварительное формирование в ориентированной УНТ неравномерной упругой деформации, которая приводит к возникновению пьезоэлектрических зарядов и форми- рованию внутренней напряженности поля в нанотрубке [18,20-22]. Последующее приложение внешнего электрического поля к неравномерно деформированной УНТ вызывает перераспределение деформации в ней и, как следствие, изменение сопротивления. Таким образом, неравномерная деформация УНТ выступает в качестве источника дополнительного сопротивления, величина которого зависит от значения протекающего тока, и приводит к возникновению в нанотрубке мемристорного эффекта.

В оксидах металлов процессом, приводящим к проявлению мемристорного эффекта, является диффузия вакансий кислорода [4]. Однако в оксидах металлов количество вакансий кислорода трудно контролировать, что приводит к низкой воспроизводимости параметров мемристорных структур на их основе [4]. Использование УНТ позволяет решить данную проблему путем формирования в них контролируемой неравномерной упругой деформации.

Целью настоящей работы является разработка методики формирования контролируемой неравномерной упругой деформации в ориентированных углеродных нанотрубках и исследование мемристорного эффекта в них.

\section{Методика эксперимента}

Методика формирования контролируемой неравномерной упругой деформации $\Delta L_{0}(x)$ в ориентированной УНТ разрабатывалась на основе метода сканирующей туннельной микроскопии (СТМ). Система управления СТМ позволяет локализовать индивидуальную УНТ, определить ее геометрические параметры и сформировать неоднородное внешнее электрическое поле $\mathrm{c}$ заданным значением напряженности $E(x, t)$. 

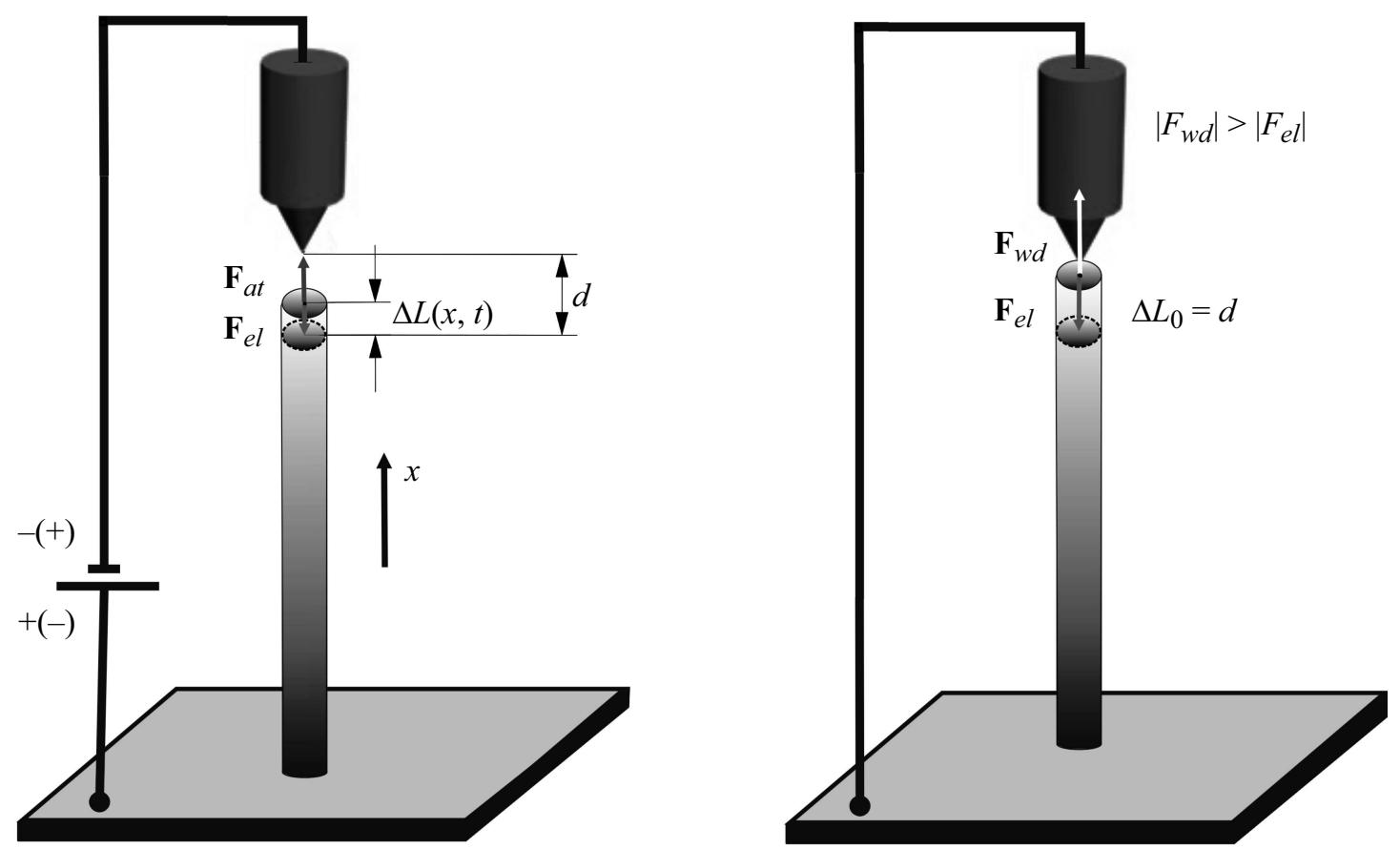

Рис. 1. Схема формирования контролируемой упругой деформации ориентированной УНТ $\Delta L_{0}$ под действием локального внешнего электрического поля: при приложении напряжения (слева) и после снятия напряжения (справа). $F_{e l}-$ упругие силы; $F_{a t}$ - электростатическая сила притяжения, $F_{w d}$ - силы Ван-дер-Ваальса [11].
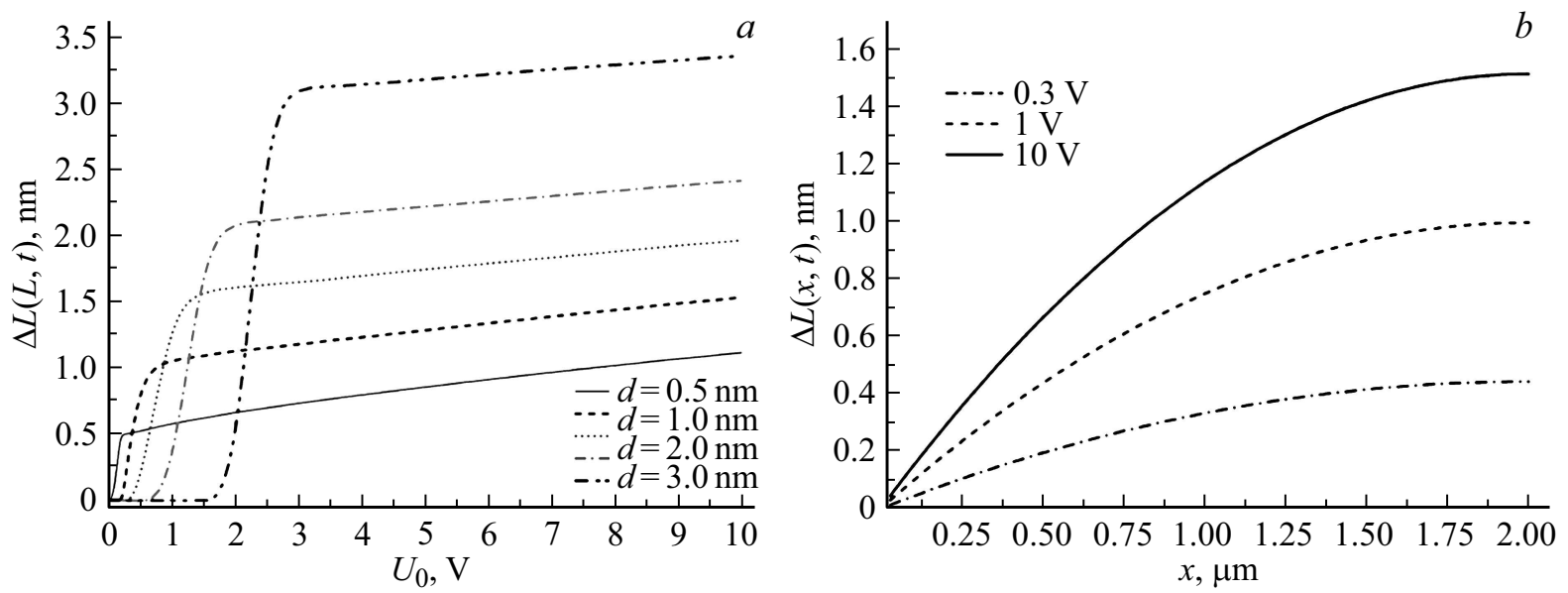

Рис. 2. Теоретические зависимости продольной деформации ориентированной УНТ от напряжения: $a$ - при различных значениях туннельного зазора $d$; $b-$ распределение вдоль оси нанотрубки $x$.

Как известно, под действием внешнего электрического поля $E(x, t)$ УНТ (длиной $L$, диаметром $D$, модулем Юнга $Y$ ) как с полупроводниковым, так и с металлическим типом проводимости, поляризуется [23-25] и между ее вершиной и зондом СТМ возникает электростатическая сила притяжения $F_{a t}(x, t)$, направленная на острие зонда $[12,26]$ :

$$
F_{a t}(x, t)=0.5 \varepsilon \varepsilon_{0} E(x, t)^{2} S,
$$

где $0 \leq x \leq L, \varepsilon_{0}-$ диэлектрическая постоянная, $\varepsilon-$ диэлектрическая проницаемость среды между вершиной
УНТ и верхним электродом, $S$ - площадь поперечного сечения УНТ.

Под действием силы притяжения $F_{a t}(x, t)$ ориентированная УНТ удлиняется на величину $\Delta L(x, t)$ (рис. 1$)$ и в ней возникают упругие силы $F_{e l}(x, t)=k \Delta L(x, t)$, где $k=192 \pi D^{4} Y / 64 L^{3}$ [26]. При значении продольной деформации, равной величине туннельного зазора $d$ $\left(\Delta L(L, t)=\Delta L_{0}=d\right)$, нанотрубка касается зонда СТМ и после снятия внешнего электрического поля удерживается на его поверхности силами Ван-дер-Ваальса $F_{w d}$ при условии, что они по модулю превосходят упругие силы $F_{e l}(L, t)$ (рис. 1). Величина напряженности внеш- 

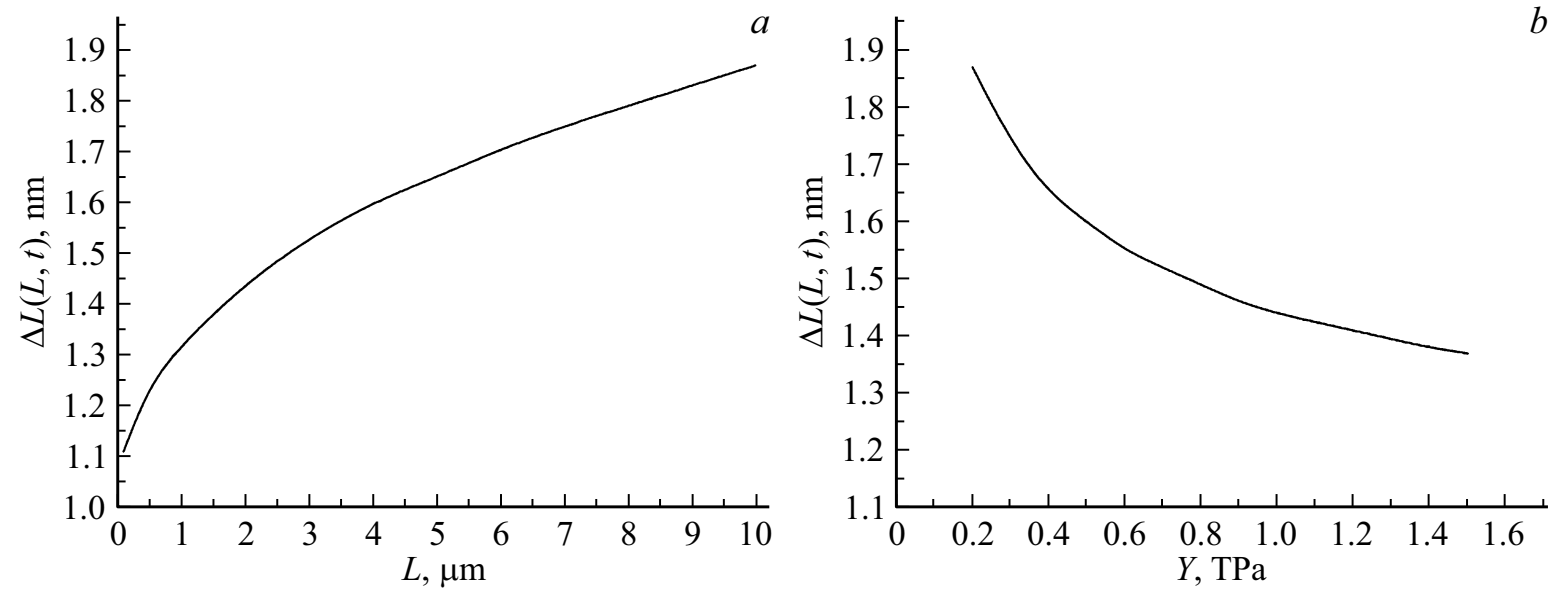

Рис. 3. Теоретические зависимости продольной деформации ориентированной УНТ: $a-$ от длины; $b-$ от модуля Юнга.

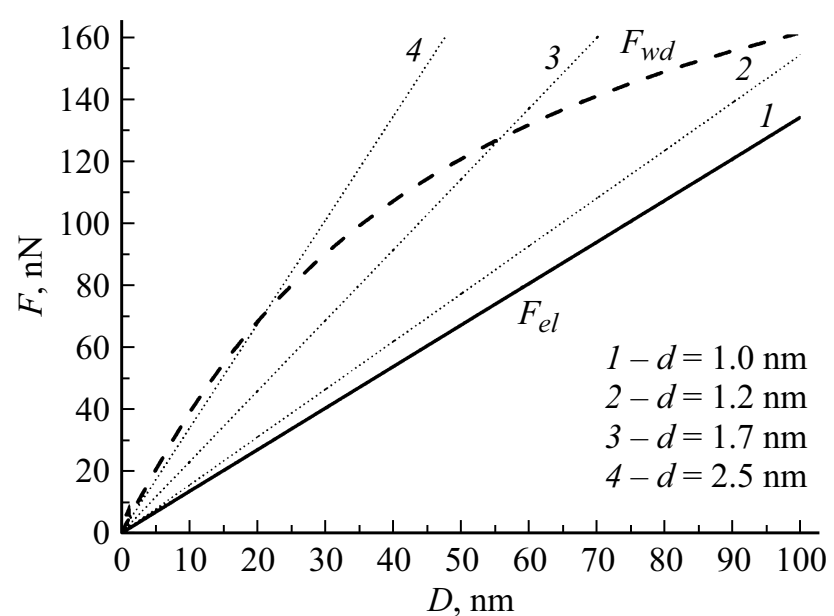

Рис. 4. Теоретические зависимости сил Ван-дер-Ваальса $\left(F_{w d}\right)$ и упругих сил $\left(F_{e l}\right)$ от диаметра ориентированной УНТ при $H=20$ для различных значений туннельного зазора $d$.

него электрического поля $E(x, t)$, необходимая для выполнения условия $\Delta L_{0} \geq d$, определялась на основании моделирования продольной деформации ориентированной УНТ.

Моделирование продольной деформации ориентированной УНТ $\Delta L(x, t)$ при приложении пилообразного импульса напряжения $U(t)$ выполнялось на основе решения дифференциального уравнения:

$$
m \frac{\partial^{2} \Delta L(x, t)}{\partial t^{2}}=F_{a t}(x, t)-Y \frac{\partial^{2} \Delta L(x, t)}{\partial x^{2}} V
$$

где $m$ - масса, $Y$ - модуль Юнга и $V$ - объем УНТ.

Решения уравнения (2) осуществлялось при выполнении начальных и граничных условий:

$$
\Delta L(x, 0)=0, \frac{\partial \Delta L(x, 0)}{\partial t} \text { и } \Delta L(0, t)=0, \frac{\partial \Delta L(L, t)}{\partial x}=0
$$

методом конечных разностей. Расчеты выполнялись для ориентированных УНТ с $L=2 \mu \mathrm{m}, D=90 \mathrm{~nm}$, $Y=1 \mathrm{TPa}$.

Зависимости деформации $\Delta L(L, t)$ ориентированной УНТ от амплитуды импульса прикладываемого напряжения $U_{0}$ при значениях туннельного зазора $d$ от 0.5 до $3.0 \mathrm{~nm}$ представлены на рис. 2, $a$. Наименьшее значение исследуемого диапазона туннельного зазора определялось из условия отсутствия сил Ван-дер-Ваальса между вершиной УНТ и верхним электродом при данном значении $d$, максимальное значение - принципом работы измерительной системы СТМ. Максимальное значение напряжения $U_{0}$ ограничивалось значением адгезионной прочности соединения ориентированной УНТ с подложкой [27].

Результаты моделирования распределения продольной деформации $\Delta L(x, t)$ вдоль оси $x$ нанотрубки при $U_{0}=0.3-10 \mathrm{~V}$ представлены на рис. 2, $b$. Зависимости величины деформации $\Delta L(L, t)$ от длины и модуля Юнга ориентированной УНТ при $d=1.0 \mathrm{~nm}$ и $U_{0}=10 \mathrm{~V}$ приведены на рис. 3.

Оценка упругих и Ван-дер-Ваальсовых сил, возникающих при касании нанотрубкой острия зонда радиусом $R_{t i p}=25 \mathrm{~nm}$, проводилась на основании результатов моделирования деформации ориентированной УНТ. Силы Ван-дер-Ваальса определялись как дисперсионное взаимодействие между неполярными частицами с площадью касания, равной $S_{c}=\left(\Delta L_{0}-d\right) \cdot 0.5 D \cdot R_{t i p} /\left(0.5 D+R_{t i p}\right)$. Зависимости упругих $\left(F_{e l}\right)$ и ван-дер-ваальсовых сил $\left(F_{w d}\right)$ от диаметра УНТ при различных значениях туннельного зазора и аспектном отношении длины к диаметру нанотрубки $H=20$ представлены на рис. 4.

Экспериментальный образец с массивом вертикально ориентированных углеродных нанотрубок (ВОУНТ) выращивался методом плазмохимического осаждения из газовой фазы (PECVD) в модуле многофункционального нанотехнологического комплекса НАНОФАБ НТК-9 (НТ-МДТ, Зеленоград) [28]. На рис. 5, a пред- 

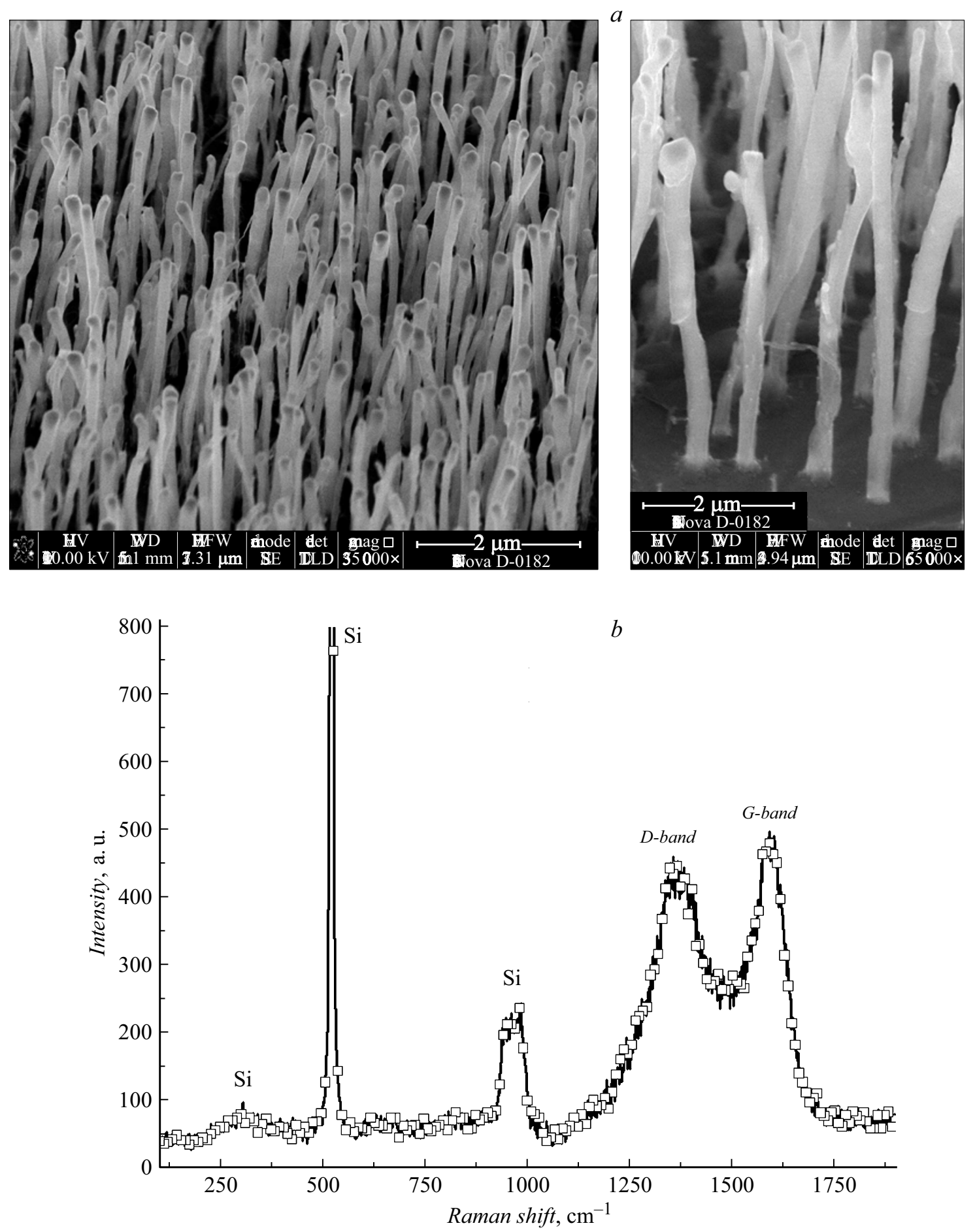

Рис. 5. Экспериментальный образец с ВОУНТ: $a-$ РЭМ изображение; $b-$ рамановский спектр.

ставлено изображение массива ВО УНТ, полученное методом растровой электронной микроскопии (РЭМ) с использованием Nova NanoLab 600 (FEI Company). Статистическая обработка РЭМ изображения показала, что высота и диаметр ВОУНТ составляли $L=2.23 \pm 0.37 \mu \mathrm{m}$ и $D=108 \pm 39 \mathrm{~nm}$ соответственно. Модуль Юнга, определенный на основе ранее разработанной методики [29], составил $Y=1.05 \pm 0.21 \mathrm{TPa}$.
Структурный анализ выращенного массива ВОУНТ проводился с использованием рамановского спектрометра Renishaw InVia Reflex (Renishaw plc, Великобритания) (рис. 5,b). Рамановские спектры экспериментального образца (рис. $5, b$ ) показали наличие $D$ - и $G$-мод, характерных для УНТ [30], и отсутствие моды RBM в диапазоне 0-200 $\mathrm{cm}^{-1}$, что указывало на их многостенность [31]. 

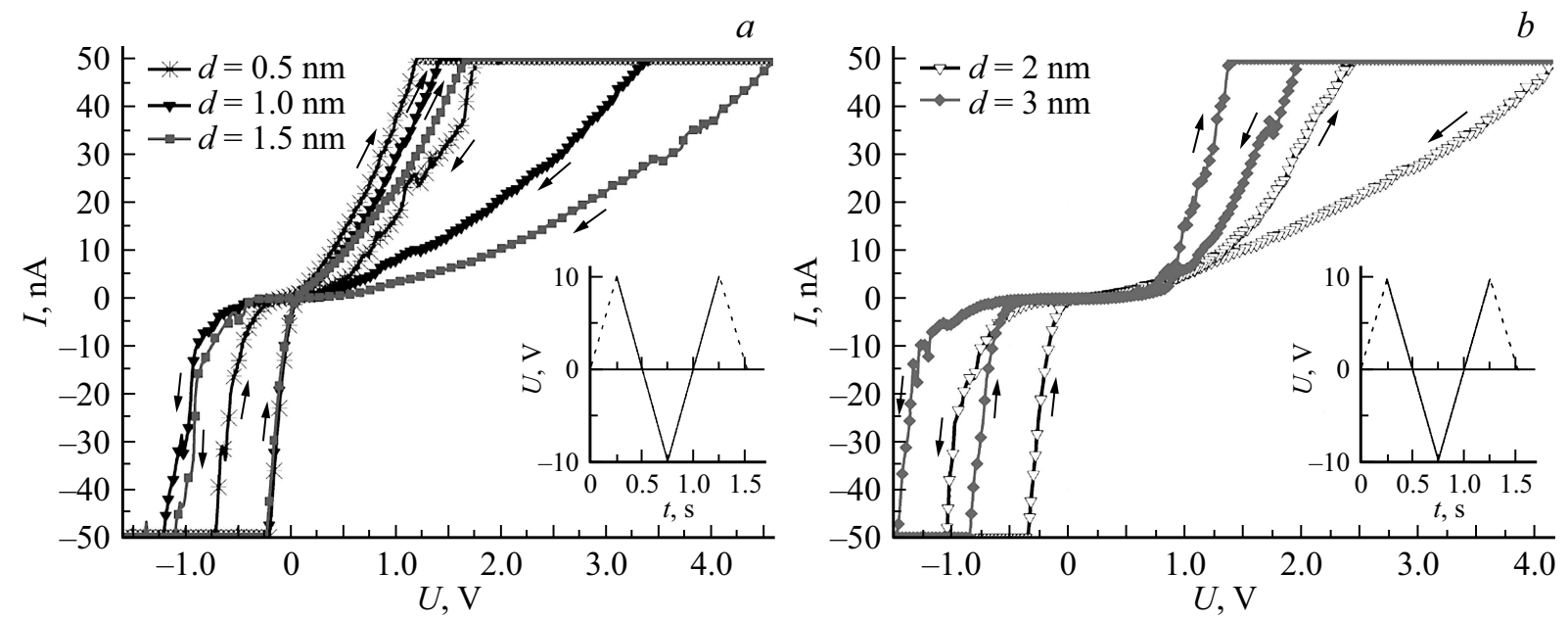

Рис. 6. ВАХ упруго деформированных УНТ $(L=2.2 \mu \mathrm{m}, D=92 \mathrm{~nm})$, полученные методом СТМ спектроскопии при приложении $\left.\left.U_{0}= \pm 10 \mathrm{~V}: a\right) d=\Delta L_{0}=0.5-1.5 \mathrm{~nm} ; b\right) d=2.0-3.0 \mathrm{~nm}$.

С использованием результатов моделирования проводились экспериментальные исследования по формированию в ВОУНТ неравномерных упругих деформаций и их влиянию на мемристорный эффект (рис. 6). Исследования выполнялись в режиме токовой спектроскопии СТМ с использованием зондовой нанолаборатории Ntegra (НТ-МДТ, Зеленоград). Для локализации над вершиной индивидуальной нанотрубки проводилось предварительное сканирование массива ВОУНТ в режиме постоянного тока СТМ. В качестве верхнего электрода в процессе измерения выступал вольфрамовый зонд СТМ радиусом $25 \mathrm{~nm}$, заточенный методом фокусированных ионных пучков [32]. В качестве нижнего электрода выступал проводящий слой, образованный на поверхности подложки кремния в процессе роста ВОУНТ [28]. Заданное значение деформации в нанотрубке формировалось в едином процессе измерения непосредственно перед снятием вольт-амперных характеристик (BAX). Момент формирования деформации ВОУНТ под действием внешнего электрического поля обозначен штрихом на импульсе прикладываемого напряжения (вставка на рис. 6). При туннельном зазоре от 0.2 до $2 \mathrm{~nm}$ между ВОУНТ и зондом СТМ прикладывались импульсы напряжения $U(t)$ с амплитудой $\pm 10 \mathrm{~V}$ и длительностью $1 \mathrm{~s}$. При этом для защиты измерительной системы и предотвращения разрушения УНТ при протекании тока большой плотности в системе СТМ установлено ограничение тока на уровне $50 \mathrm{nA}$.

\section{Результаты и обсуждения}

Результаты моделирования деформации $\Delta L(L, t)$ ориентированной УНТ ( $L=2 \mu \mathrm{m}, D=90 \mathrm{~nm}, Y=1 \mathrm{TPa})$ на основе выражения (2) показали, что ВОУНТ касается зонда СТМ для $d=1.0-3.0 \mathrm{~nm}$ при $E(L, t) \approx 10^{9} \mathrm{~V} / \mathrm{m}$ (рис. 2,a). При этом на начальном участке зависимостей $\left(E(L, t)<10^{9} \mathrm{~V} / \mathrm{m}\right)$ деформация нанотрубки близка к нулю, при достижении порогового значения $E(L, t)=10^{9} \mathrm{~V} / \mathrm{m}$ наблюдается скачкообразное изменение деформации и нанотрубка касается зонда (рис. 2,a), что связано с нелинейным ростом напряженности внешнего электрического поля $E(L, t)=U(t) /(d-\Delta L(L, t))$ в процессе удлинения УНТ. После контакта с зондом СТМ зависимость деформации ориентированной УНТ входит в насыщение (рис. 2,a), что связано с тем, что наибольшее значение напряженности внешнего электрического поля сосредоточено в области острия зонда и нанотрубка удерживается полем в пределах данной области. Для $d=0.5 \mathrm{~nm}$ пороговое значение напряженности внешнего электрического поля уменьшается до $E(L, t)=0.4 \mathrm{~V} / \mathrm{m}$, что связано с влиянием сил Ван-дерВаальса, возникающих между вершиной ориентированной УНТ и зондом СТМ на расстоянии около $0.2 \mathrm{~nm}$.

Результаты моделирования деформации ориентированной УНТ $(d=1 \mathrm{~nm})$ вдоль оси $x$ показали (рис. $2, b)$, что деформация $\Delta L(x, t)$ носит неравномерный характер: вблизи основания нанотрубки $\Delta L(0, t) \approx 0$, а на вершине УНТ деформация $\Delta L(L, t)$ достигает максимального значения. При этом с увеличением величины прикладываемого напряжения $U_{0}$ градиент деформации $(d \Delta L(x, t) / d x)$ увеличивается.

Результаты моделирования деформации ориентированной УНТ, полученные на основании выражения (2), также показали, что удлинение нанотрубки под действием локального внешнего электрического поля возрастает при увеличении ее длины (рис. $3, a$ ), уменьшается при увеличении модуля Юнга (рис. $3, b$ ) и не зависит от ее диаметра. Таким образом, чем меньше длина и больше модуль Юнга УНТ, тем большее значение напряженности внешнего электрического поля $E(L, t)$ требуется для выполнения условия $\Delta L(L, t) \geq d$. При этом диаметр УНТ может изменяться в широком диапазоне значений при условиях, что $d \ll D$ и количество слоев нанотрубки постоянно. Однако необходимо учитывать, что на прак- 
тике при увеличении диаметра УНТ может наблюдаться рост количества слоев нанотрубки, что вызовет возникновение дополнительных сил Ван-дер-Ваальса между слоями и увеличение модуля Юнга нанотрубки, и, как следствие, уменьшение ее деформации под действием внешнего электрического поля [29,33].

Таким образом, при приложении локального внешнего электрического поля посредством СТМ в ВОУНТ формируется неравномерная упругая деформация. Значение деформации ориентированной УНТ определяется величиной туннельного зазора и амплитудой импульса прикладываемого напряжения, а значение внешнего электрического поля, необходимое для выполнения условия $\Delta L(L, t) \geq d$, зависит от длины и модуля Юнга нанотрубки.

После снятия внешнего электрического поля $E(x, t)$ наблюдается релаксация деформации $\Delta L(x, t)$ нанотрубки. При этом может происходить либо полная релаксация деформации, когда силы Ван-дер-Ваальса становятся недостаточными для удержания вершины нанотрубки на острие зонда, либо частичная - значение деформации становится равной величине туннельного зазора $\left(\Delta L_{0}=d\right)$ при условии, что силы Ван-дер-Ваальса превосходят упругие силы нанотрубки.

Оценка зависимостей, представленных на рис. 4, показала, что силы Ван-дер-Ваальса превосходят по модулю упругие силы в 1.5-5 раз, когда аспектное отношение нанотрубки составляет $H \approx 20-30$. Данные зависимости также позволили оценить максимально допустимые значения деформации УНТ $\Delta L_{0}$ и туннельного зазора, при которых выполняется условие $\left|F_{w d}\right|>\left|F_{e l}(L, t)\right|$. Так, увеличение деформации нанотрубки $\Delta L_{0}$ будет приводить к линейному увеличению тангенса угла наклона зависимости упругих сил $F_{e l}$ и пересечению с зависимостью сил Ван-дер-Ваальса, которая не зависит от $d$ (рис. 4). В результате для ориентированной УНТ с $Y=1$ ТРа при $D=100 \mathrm{~nm}$ и $L=2 \mu$ т величина $\Delta L_{0}=d$ должна составлять менее $1.2 \mathrm{~nm}$; при $D=50 \mathrm{~nm}$ и $L=1 \mu \mathrm{m}$ величина $\Delta L_{0} \leq 1.7 \mathrm{~nm}$, а при $D=10 \mathrm{~nm} \mathrm{и}$ $L=200 \mathrm{~nm}$ величина $\Delta L_{0} \leq 2.5 \mathrm{~nm}$ (рис. 4).

Таким образом, при выполнении условия $\left|F_{w d}\right|>\left|F_{e l}(L, t)\right|$, в ориентированной УНТ возможно формирование контролируемой неравномерной упругой деформации, значение которой определяется величиной туннельного зазора. Создание контролируемой неравномерной упругой деформации в углеродной нанотрубке как с полупроводниковым, так и с металлическим типом проводимости является необходимым условием для возникновения в ней внутреннего электрического поля, связанного с проявлением флексо- и пьезоэлектрических эффектов [20-22]. При этом формирование в УНТ внутреннего электрического поля приводит к наблюдению воспроизводимого мемристорного эффекта в ней [11].

На рис. 6 представлены ВАХ упруго деформированной ВОУНТ $(L=2.2 \mu \mathrm{m}, D=92 \mathrm{~nm})$, выделенной из массива ВОУНТ методом СТМ, для разных значений туннельного зазора, полученные при приложении пилообразного импульса напряжения амплитудой $\pm 10 \mathrm{~V}$ (вставка рис. 6). Анализ полученных ВАХ показал, что при выполнении условия формирования в нанотрубке контролируемой деформации $\left(\left|F_{w d}\right|>\left|F_{e l}(L, t)\right|\right.$ при $\left.\Delta L_{0}=d \leq 1.5 \mathrm{~nm}\right)$ с увеличением значения абсолютной деформации $\Delta L_{0}$ от 0.5 до $1.5 \mathrm{~nm}$ (относительной деформации от 0.02 до $0.07 \%$ ) возрастает ее сопротивление в высокоомном состояния $R_{H R}$ от 48 до $252 \mathrm{M} \Omega$ и площадь петли гистерезиса ВАХ увеличивается от 28 до $115 \mathrm{nW}$ (рис. $6, a$ ), что связано с ростом внутреннего электрического поля УНТ $E_{\mathrm{def}}\left(\Delta L_{0}\right)$ [8]. При малой деформации $\left(\Delta L_{0}=0.5 \mathrm{~nm}\right)$ сопротивления нанотрубки в высокоомном $R_{H R}$ и низкоомном $R_{L R}$ состояниях незначительно отклоняются от сопротивления, определяемого ее удельным сопротивлением. При дальнейшем росте деформации $\Delta L_{0}$ определяющую роль в формировании сопротивления нанотрубки играет пьезоэлектрическое поле, возникающее в результате формирования неравномерной упругой деформации [11]. Необходимо отметить, что сопротивление ВОУНТ в низкоомном состоянии не сильно зависит от величины деформации $\Delta L_{0}$, так как исходное пьезоэлектрическое поле нанотрубки на данном участке ВАХ сонаправлено с внешним полем [11].

При увеличении относительной деформации до $0.14 \%(d=2.0-3.0 \mathrm{~nm})$, когда не выполняется условие $\left|F_{w d}\right|>\left|F_{e l}(L, t)\right|$ (рис. 6,b), вершина нанотрубки остается подвижной в процессе измерения, и после снятия внешнего электрического поля нанотрубка возвращается в недеформированное состояние. При этом увеличение туннельного зазора до 2.0-3.0 nm при измерении ВАХ нанотрубки приводит к увеличению сопротивления $R_{L R}$ и уменьшению RHR и, как следствие, к возникновению петли гистерезиса (рис. 6, $b$ ). Увеличение сопротивления $R_{L R}$ вызвано отсутствием стабильного контакта вершины нанотрубки с острием зонда СТМ. Уменьшение сопротивления $R_{H R}$ нанотрубки, вероятно, связано с эмиссионными процессами, влияние которых возрастает с ростом величины туннельного зазора. Таким образом, при превышении максимально допустимого значения деформации ВОУНТ также наблюдается гистерезис ВАХ, связанный с постепенной деформацией нанотрубки в процессе измерения и влиянием эмиссионных процессов. Однако нанотрубки, испытывающие такие деформации, не могут быть использованы для создания на их основе мемристорных структур, так как наблюдается полная релаксация деформации нанотрубки после снятия внешнего электрического поля.

\section{Заключение}

В настоящей работе предложена методика формирования контролируемой неравномерной упругой деформации ориентированной УНТ для разработки мемристорных структур с воспроизводимыми параметрами. Проведено моделирование продольной деформации ори- 
ентированной УНТ под действием локального внешнего электрического поля. Установлено, что значение продольной деформации нанотрубки определяется величиной туннельного зазора СТМ и амплитудой прикладываемого напряжения. При этом значение внешнего электрического поля, необходимое для создания заданного значения деформации, зависит от длины и модуля Юнга нанотрубки. Проведена оценка упругих и ван-дерваальсовых сил, возникающих при продольной упругой деформации ориентированной УНТ $\left(\Delta L_{0}=0.5-3.0 \mathrm{~nm}\right)$, и показано, что аспектное отношение нанотрубки должно составлять 20-30 для контроля деформации на заданном значении после снятия внешнего электрического поля.

Проведены экспериментальные исследования влияния деформации на мемристорный эффект упруго деформированных углеродных нанотрубок. Показано, что увеличение значения контролируемой неравномерной упругой деформации нанотрубки от 0.5 до $1.5 \mathrm{~nm}$ (от 0.02 до $0.07 \%$ ) вызывает рост ее сопротивления в высокоомном состоянии почти в 5 раз, что приводит к усилению мемристорного эффекта за счет роста внутреннего электрического поля нанотрубки. При превышении максимально допустимого значения деформации, соответствующего состоянию, когда упругие силы в нанотрубке превышают силы Ван-дер-Ваальса, нанотрубка остается подвижной в процессе измерения и релаксирует после снятия внешнего электрического поля. В результате чего при малых напряжениях (менее $1 \mathrm{~V}$ ) переключения сопротивления ВОУНТ не наблюдается, а при увеличении напряжения на значение сопротивления оказывают влияние эмиссионные процессы. Таким образом, формирование мемристорных структур на основе углеродных нанотрубок возможно только при наличии неравномерной упругой деформации в отсутствии внешнего электрического поля.

Проведенные исследования направлены на развитие междисциплинарного научного направления - „стрейнтроники“, в котором используется влияние механических деформаций в наноразмерных материалах на их электрические свойства для создания новых электронных устройств. Полученные результаты могут быть использованы при разработке перспективных элементов наносистемной техники и наноэлектроники на основе контролируемых деформаций ориентированных УНТ, в частности мемристорных структур с воспроизводимыми параметрами.

Результаты получены с использованием оборудования Научно-образовательного центра и Центра коллективного пользования „Нанотехнологии“ Южного федерального университета.

Работа выполнена при финансовой поддержке Российского фонда фундаментальных исследований (проект № 16-29-14023 офи_м) и гранта Южного федерального университета (проект № ВнГр-07/2017-26).

\section{Список литературы}

[1] Meena J.S., Sze S.M., Chand U., Tseng T.-Y. // Nanoscale Res. Lett. 2014. Vol. 9. N 1. P. 1-33.

[2] Zhu J.G. // Proc. IEEE. 2008. Vol. 96. P. 1786-1798.

[3] Raoux S., Burr G.W., Breitwisch M.J., Rettner C.T., Chen Y.-Ch., Shelby R.M., Salinga M., Krebs D., Chen Sh.-H., Lung H.-L., Lam Ch.H. // IBM J. Res. Dev. 2008. Vol. 52. N 4/5. P. 465-479.

[4] Akinaga H., Shima H. // Proc. IEEE. 2010. Vol. 98. N 12. P. 2237-2251.

[5] Chua L.O. // Proc. IEEE. 2003. Vol. 91. N 11. P. 1830-1859.

[6] Yang J.J., Strukov D.B., Stewart D.R. // Nature Nanotech. 2013. Vol. 8. P. 13-24.

[7] Chua L.O. // Appl. Phys. A. 2011. Vol. 102. P. 765-783.

[8] Strukov D.B., Snider G.S., Stewart D.R., Williams R.S. // Nature. 2008. Vol. 453. P. 80-83.

[9] Rueckes T., Kim K., Joselevich E., Tseng G.Y., Cheung C.-L., Lieber C.M. // Science. 2000. Vol. 289. N 7. P. 94-97.

[10] Ren Z., Lan Y., Wang Y. Aligned Carbon Nanotubes: Physics, Concepts, Fabrication and Devices. NanoScience and Technology. Berlin: Springer, 2013. 299 p.

[11] Ilina M.V., Il'in O.I., Blinov Yu.F., Smirnov V.A., Kolomiytsev A.S., Fedotov A.A., Konoplev B.G., Ageev O.A. // Carbon. 2017. Vol. 123. P. 514-524.

[12] Агеев О.А., Блинов Ю.Ф., Ильин О.И., Коноплев Б.Г., Рубашкина М.В., Смирнов В.А., Федотов А.А. // ФТТ. 2015. № 4. C. 807-813. [Ageev O.A., Blinov Yu.F., Ilin O.I., Konoplev B.G., Rubashkina M.V., Smirnov V.A., Fedotov A.A. // Phys. Sol. Stat. 2015. Vol. 57. N 4. P. 825831].

[13] Bartolomeo A.D., Scarfato A., Giubileo F., Bobba F., Biasiucci M., Cucolo A.M., Santucci S., Passacantando M. // Carbon. 2007. Vol. 45. P. 2957-2971.

[14] Gorodetskiy D.V., Gusel'nikov A.V., Shevchenko S.N., Kanygin M.A., Okotrub A.V., Pershin Y.V. // J. Nanophotonics. 2016. Vol. 10. N 1. P. 012524.

[15] Zuo Y., Ren Y., Wang Z., Han X., Xi L. // Organic Electronics. 2013. Vol. 14. P. 2306-2314.

[16] Parveen Sh., Husain S., Kumar A., Ali J., Husain H., Husain M. // ISRN Nanomaterials. 2012. V. 2012. N. 971854. P. $1 ? 5$.

[17] Агеев О.А., Блинов Ю.Ф., Ильин О.И., Коломийцев А.С., Коноплев Б.Г., Рубашкина М.В., Смирнов В.А., Федотов А.А. // ЖТФ. 2013. Т. 83. Вып. 12. C. 128-133. [Ageev O.A., Blinov Yu.F., Il'in O.I., Kolomiitsev A.S., Konoplev B.G., Rubashkina M.V., Smirnov V.A., Fedotov A.A. // Tech. Phys. 2013. Vol. 58. N 12. P. 1831-1836.]

[18] Liu B., Jiang H., Johnson H.T., Huang Y. // J. Mech Phys. Sol. 2004. Vol. 52. P. 1-26.

[19] Nakayama Y., Nagataki A., Suekane O., Cai X., Akita S. // Jpn. J. Appl. Phys. 2005. Vol. 44. N 23. P. 720-722.

[20] Zelisko M.A., Hanlumyuang Y.B., Yang S.C., Liu Y.D., Lei C.D., Li J.D., Ajayan P.M.C., Sharma P. // Nat. Commun. 2014. Vol. 5. P. 1-7.

[21] Chandratre S., Sharma P. // Appl. Phys. Lett. 2012. Vol. 100. P. 023114.

[22] Maranganti R., Sharma N.D., Sharma P. // Phys. Rev. B. 2006. Vol. 74. P. 014110.

[23] Lu W., Wang D., Chen L. // Nano Lett. 2007. Vol. 7. N 9. P. 2729-2733. 
[24] Kozinsky B., Marzari N. // Phys. Rev. Let. 2006. Vol. 96. P. 166801.

[25] Mayer A. // Phys. Rev. B. 2005. Vol. 71. P. 235333.

[26] Dietzel D., Marsaudon S., Aime J.P., Nguyen C.V., Couturier G. // Phys. Rev. B. 2005. Vol. 72. P. 035445.

[27] Агеев О.А., Блинов Ю.Ф., Ильина М.В., Ильин О.И., Смирнов В.А., Цуканова О.Г. // ФТТ. 2016. № 2. С. 301-306. [Ageev O.A., Blinov Yu.F., Ilina M.V., Ilin O.I., Smirnov V.A., Tsukanova O.G. // Phys. Sol. Stat. 2016. Vol. 58. N 2. P. 309314.]

[28] Ageev O.A., Balakirev S.V., Bykov Al.V., Gusev E.Yu., Fedotov A.A., Jityaeva J.Y., Ilïn O.I., Ilina M.V., Kolomiytsev A.S., Konoplev B.G., Krasnoborodko S.U., Polyakov V.V., Smirnov V.A., Solodovnik M.S., Zamburg E.G. Development of new metamaterials for advanced element base of micro- and nanoelectronics, and microsystem devices. Chapter In: Advanced Materials - Manufacturing, Physics, Mechanics and Applications. Ed. by I.A. Parinov, Sh.-H. Chang, V.Yu. Topolov. Switzerland: Springer International Publishing, 2016. P. 563-580

[29] Агеев О.А., Ильин О.И., Коломийцев А.С., Коноплев Б.Г., Рубашкина М.В., Смирнов В.А., Федотов А.А.] // Рос. нанотехнологии. 2012. Т. 7. № 1-2. С. 54-59. [Ageev O.A., Il'in O.I., Kolomiitsev A.S., Konoplev B.G., Rubashkina M.V., Smirnov V.A., Fedotov A.A. // Nanotechnol. Russ. 2012. Vol. 7. N 1-2. P. 47-53.]

[30] Maultzsch J., Reich S., Thomsen C. // Phys. Rev. B. 2002. Vol. 65. P. 233402.

[31] Saito R., Hofmann M., Dresselhaus G., Jorio A., Dresselhaus M.S. // Advanc. Phys. 2011. Vol. 60. N 3. P. 413550.

[32] Коноплев Б.Г., Агеев О.А., Смирнов В.А., Коломийцев А.С., Сербу Н.И. // Микроэлектроника. 2012. Т. 41. № 1. C. 47-56. [Konoplev B.G., Ageev O.A., Smirnov V.A., Kolomiitsev A.S., Serbu N.I. // Russian Microelectronics. 2012. Vol. 41. N 1. P. 41-50.]

[33] Liu L., Cao G., Chen X. // J. Nanomater. 2008. Vol. 2008. P. 271763. 